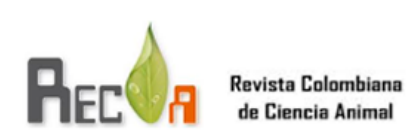

Revista Colombiana de Ciencia Animal ISSN: 2027-4297

reciaeditor@unisucre.edu

Universidad de Sucre

Colombia

\title{
Parâmetros na utilização de silagem de grão úmido de milho na bovinocultura de corte
}

Augusto Pereira, Kárito; Vaz Ribeiro, Renata; Rodrigues de Oliveira, Anderson; das Graças Amaral, Alliny Parâmetros na utilização de silagem de grão úmido de milho na bovinocultura de corte

Revista Colombiana de Ciencia Animal, vol. 11, núm. 1, 2019

Universidad de Sucre, Colombia

DOI: https://doi.org/10.24188/recia.v11.n1.2019.622

Los autores permiten a RECIA reimprimir el material publicado en él. En caso de que un autor quiera traducir o usar una publicación parcial o completa de nuestro Diario, el autor debe obtener un permiso por escrito del editor de la revista.

Esta obra está bajo una Licencia Creative Commons Atribución 4.0 Internacional. 


\section{Parâmetros na utilização de silagem de grão úmido de milho na bovinocultura de}

\section{corte}

Parameters in use silage grain moist corn in cattle court

Parámetros en la utilización de silaje de grano húmedo de maíz en la bovinocultura de corte

Kárito Augusto Pereira

DOI: https://doi.org/10.24188/recia.v11.n1.2019.622

Universidade Federal dos Vales do Jequitinhonha e Mucuri

(UFVJM), Departamento de Zootecnia. Minas Gerais,

Brasil

karitoalgusto@gmail.com

(iD http://orcid.org/0000-0002-6749-4610

Recepção: 17 Abril 2018

Aprovação: 12 Março 2019

Publicado: 15 Abril 2019

Renata Vaz Ribeiro

Universidade Federal de Goiás (UFG), Departamento de

Zootecnia. Goinia, Goias, Brasil

renata.vaz.ribeiro@hotmail.com

(iD) http://orcid.org/0000-0001-9099-1204

Anderson Rodrigues de Oliveira

Universidade Federal dos Vales do Jequitinhonha e Mucuri

(UFVJM), Departamento de Zootecnia. Minas Gerais,

Brasil

andersonr.deoliveira@outlook.com

(iD http://orcid.org/0000-0003-3710-2695

Alliny das Graças Amaral

Universidade Estadual de Goiás (UEG) - Câmpus São

Luis de Montes Belos. Goiás, Brasil

allinyamaral@gmail.com

(iD http://orcid.org/0000-0002-1418-9698

\section{Resumo:}

Objetivou-se, por meio do presente trabalho, reunir aporte teórico, via revisão da literatura, sob alguns parâmetros na utilização de silagem de grão úmido de milho referentes à bovinocultura de corte. Demonstrando as perspectivas de produção e importância que o milho representa para a alimentação animal. Com uma crescente demanda na produção de milho a fim de atender as necessidades do crescimento de sistemas de confinamentos, somam fatores que contribuem com maior importância na utilização de grãos na elaboração de dietas na bovinocultura, sendo considerado como a principal fonte de energia em dietas de bovinos de corte. Visto que o cenário da produção de carne bovina se torna cada vez mais competitivo, demostrando sua eficiência na digestibilidade e elevando os índices de produção, apresentando resultando satisfatórios referentes à eficiência alimentar e composição da carcaça como força de cisalhamento, $\mathrm{pH}$, cor, maciez sensorial, suculência e sabor da carne e aumento no teor de lipídios na carne dos animais que recebem dietas de silagem de grão úmido de milho, além de reduzir o dispêndio no transporte e armazenamento, concentrando a operação de moagem. Assim, a presente revisão versa sobre a viabilidade da utilização da silagem de grão úmido de milho, por se tratar de umas da poucas praticas que consegue reunir baixos custos em relação a silagem de milho convencional, aliada a elevada qualidade nutricional, sobretudo com alta resposta animal, com o objetivo de maximizar a digestibilidade do amido, sendo esta a característica de maior evidencia.

Palavras-Chave: alimentação animal, bovinos, digestibilidade, ensilagem. 


\section{Abstract:}

The objective of this study was to present a theoretical contribution, through a review of the literature, under some parameters in the use of corn silage for beef cattle. Demonstrating the production prospects and importance that maize represents for animal feed. With a growing demand for maize production in order to meet the needs of the growth of feedlot systems, there are factors that contribute with greater importance in the use of grains in the elaboration of diets in the bovinocultura, being considered as the main source of energy in diets of beef cattle. As the beef production scenario becomes increasingly competitive, demonstrating its efficiency in the digestibility and raising production rates, presenting satisfactory results regarding feed efficiency and carcass composition as shear force, $\mathrm{pH}$, color, sensorial softness, succulence and taste of the meat and increase in the lipid content in the meat of the animals receiving diets of corn grain silage, besides reducing the transport and storage expenses, concentrating the grinding operation. Thus, the present review deals with the feasibility of using corn silage, because it is one of the few practices that can achieve low costs in relation to conventional corn silage, combined with high nutritional quality, especially with a high response rate with the objective of maximizing the digestibility of the starch, being this the characteristic of greater evidence.

KEYWORDS: animal feed, cattle, digestibility, silage.

\section{RESUMEN:}

El objetivó del presente estudio fue reunir aporte teórico, vía revisión de la literatura, bajo algunos parámetros en la utilización de silaje de grano húmedo de maíz referentes a la bovino cultura de corte. Demostrando las perspectivas de producción e importancia que el maíz representa para la alimentación animal. Con una creciente demanda en la producción de maíz para atender las necesidades del crecimiento de sistemas de confinamientos, suman factores que contribuyen con mayor importancia en la utilización de granos en la elaboración de dietas en la bovocultura, siendo considerado como la principal fuente de energía en dietas de dietas bovinos de corte. Como el escenario de la producción de carne bovina se vuelve cada vez más competitivo, demostrando su eficiencia en la digestibilidad y elevando los índices de producción, presentando resultando satisfactorios referentes a la eficiencia alimentaria y composición de la carcasa como fuerza de cizallamiento, $\mathrm{pH}$, color, suavidad sensorial, suculencia y sabor de la carne y aumento en el contenido de lípidos en la carne de los animales que reciben dietas de silaje de grano húmedo de maíz, además de reducir el gasto en el transporte y almacenamiento, concentrando la operación de molienda. Así, la presente revisión versa sobre la viabilidad de la utilización del silaje de grano húmedo de maíz, por tratarse de unas pocas prácticas que logra reunir bajos costos en relación al silaje de maíz convencional, aliada a la elevada calidad nutricional, sobre todo con alta respuesta animal, con el objetivo de maximizar la digestibilidad del almidón, siendo ésta la característica de mayor evidencia.

Palabras clave: alimentación animal, bovinos, digestibilidad, ensilado.

\section{INTRODUÇÃO}

Com a globalização do mercado, a pecuária vem sofrendo profundas modificações com o objetivo de atingir índices zootécnicos mais eficientes. $\mathrm{O}$ mercado consumidor por sua vez, esta mais exigente e vem pressionando os produtores a adotarem medidas de controle de qualidade e eficiência na produção de alimentos em todas as fases da bovinocultura de corte (1).

Diante da necessidade, para se chegar a desejados índices zootécnicos, é imperativo a utilização de grãos, os quais em geral representam grande importância na alimentação de bovinos. Entretanto, é imperativo que o amido presente no grão esteja mais disponível para a digestão e aproveitamento do animal. Essa disponibilidade pode ser melhorada através de processamentos físico-químicos, nessa conjuntura destacando-se a ensilagem dos grãos úmidos de milho como uma tecnologia eficiente (2).

Partindo do pressuposto que em sistemas de produção animal, como leite e carne, geralmente a utilização de dietas de alto concentrado é à base de grãos de cereais, então faz-se necessário a conservação dos mesmos. Para o pecuarista tradicional no Brasil, que produz seu animal e seu milho, o processamento do grão úmido, é uma excelente tecnologia, devido a sua eficiência tanto qualitativa quanto quantitativa de conservação de matérias primas empregadas na alimentação animal (3).

Assim, a silagem de grão úmido de milho tem sido utilizada para solucionar problemas de armazenamento de matérias-primas nas propriedades rurais, melhorando tanto o valor nutricional deste alimento, bem como a redução do grau de contaminação das dietas dos animais. 
Ressalva que esse tipo de silagem apresenta diversas finalidades em sistemas de criação animal, e pode ser encontrado em proporções significativas em alimentos concentrados para bovinos, a fim de suprir a energia digestível suficiente objetivando melhores resultados e desempenho (4). Uam vez que, a participação de alimentos concentrados nas formulações de dietas de bovinos aumentou consideravelmente no Brasil (5).

Do mesmo modo, como na confecção da silagem de milho, utilizando a planta inteira, os mesmos cuidados são essenciais para o processamento da ensilagem de grãos para preservar a qualidade do grão úmido (6). Outros cuidados a serem intensificados bem como a prevenção de roedores no armazenamento dos grãos são essenciais a dietas dos animais, pois, além dos ricos de contaminação as perdas na estocagem são extremamente consideráveis, elevando os custos na produção.

Esta é uma tecnologia que podem ser utilizadas nos mais diversos níveis de produção a alimentação de bovinos, porém cuidados específicos são necessários a fim de produzir alimento conservado, com qualidade.

Objetivou-se, por meio do presente trabalho, reunir aporte teórico, via revisão da literatura, referênte à alguns parâmetros na utilização de silagem de grão úmido de milho na bovinocultura corte.

Estimativas e Perspectivas sobre o Milho Grão no Brasil. O milho é uma cultura que permite duas safras ao ano no Brasil, a maior é a de verão. Diante de uma produção expressiva, o milho é o cereal de maior volume de produção no mundo, com aproximadamente 960 milhões de toneladas, Estados Unidos, China, Brasil e Argentina são os maiores produtores do produto, representando $70 \%$ da produção mundial. $\mathrm{O}$ milho no Brasil representa uma área agrícola de 60 milhões de hectares, ocupando $7 \%$ do total de terras brasileiras, estimado em 851 milhões de hectares, aproximadamente 5,5 milhões de imóveis rurais, sendo considerado um país estratégico, pois, é o terceiro maior produtor e o segundo maior exportador mundial de milho, se tornando um país de grande importância dentro do cenário agrícola mundial, como identifica-se através da Tabela 1 (7).

TABELA 1

Comparativo de área, produtividade e produção - milho primeira safra no Brasil.

\begin{tabular}{lllllll}
\hline & \multicolumn{3}{l}{ Area (em mil ha) } & \multicolumn{2}{l}{$\begin{array}{l}\text { Produtividade } \\
\text { (em kg/ha) }\end{array}$} & Produção (em mil t) \\
\cline { 2 - 7 } Regiões & Safra & Safra & Safra & Safra & Safra & Safra \\
Norte & $14 / 15$ & $15 / 16$ & $14 / 15$ & $15 / 16$ & $14 / 15$ & $15 / 16$ \\
Nordeste & 393,5 & 385,1 & 3.240 & 3.223 & $1.274,70$ & $1.240,90$ \\
Centro-Oeste & 361,6 & 325,5 & 7.054 & 7.556 & $2.550,90$ & $2.459,40$ \\
Sudeste & $1.434,50$ & $1.395,10$ & 5.437 & 5.787 & $7.799,80$ & $8.073,10$ \\
Sul & $1.985,20$ & 1985,9 & 7.373 & 7.048 & $14.637,20$ & $12.587,10$ \\
Brasil & $6.234,70$ & $5.893,70$ & 4.929 & 4.832 & $30.731,40$ & $28.480,40$ \\
Fonte: Conab (8). & & & & & & \\
\hline
\end{tabular}

Informações compiladas pelo MAPA (9), o consumo interno de milho em 2013 representou 66,7\% da produção, e deve continuar nos próximos anos para $66,9 \%$, a fim de manter o consumo interno projetado de 62,6 milhões de toneladas e garantir um volume razoável de estoques finais e o nível de exportações projetado como ocorreu em 2015 que superou 2014, estima-se uma projeção de 93 milhóes de toneladas atendera a demanda em 2023 (8).

Nesse ótica, espera-se do Brasil um crescimento de 2,67\% ao ano nos próximos anos na produçâo de milho, com aumento de $0,73 \%$ da área plantada. Vários estudos e projeções realizados pela Assessoria de Gestão Estratégica do Ministério da Agricultura Pecuária e Abastecimento (MAPA) indicam aumento de 
19,11 milhões de toneladas entre a safra de 2008/2009 e 2019/2020. Estima-se que na safra de 2019/2020, a produção deverá ficar em 70,12 milhões de toneladas e o consumo em 56,20 milhões de toneladas (9).

Todavia, o milho grão apresenta-ra desafios na produção, com uma população mundial de 7 bilhões de pessoas, em que 2050 superará 9 bilhões, o milho será ainda o mais importante dentro desta estratégia. Pois, a demanda por alimentos crescerá $20 \%$ nos próximos 10 anos, e o Brasil será responsável por atender $40 \%$ desta demanda. Além de outros desafios como a escassez de terras, variações climáticas, tornando cada vez mais necessário o uso de tecnologia e de práticas de manejo que permitam colher mais por área a fim de aumentar a produtividade (7).

Importâncias do Milho em Dietas na Bovinocultura de Corte. É insofismável que a adoção de estratégias corretas, a fim de maximizar produção de milho é sem duvidas indispensável para atender as necessidades do mesmo, visto que o consumo de carne bovina na China é $4 \mathrm{~kg} /$ habitante/ano, enquanto que os brasileiros consomem 39,5 Kg de carne bovina por habitante/ano. Assim, para atender essa demanda de proteína animal, destaca-se a utilização do milho na ração animal sendo considerado como a principal fonte de energia mais importante em dietas de bovinos de corte (10).

Tornando irrefutável a importância do milho dentro na cadeia produtiva de alimentos de origem animal, pois representa a produção agrícola mundial mais expressivo e, provavelmente, o cereal mais importante, para toda a humanidade quando se consideram os volumes físicos, valor econômico e o alcance social e geográfico da produção (11).

A partir da Figura 1, é possivel observar a evolução da produção de milho no país nos ultimos 28 anos, reafimando sua repretentativaidade do ceral no mercado mundial. E possivel notar que a a inversão na produção de milho entre a primeira e segunda sagra ocorreu a partir de 2011/2012. Fazendo necessário reiterar a safra recorde de 2016/2017 de toda a serie histórica , com previsões na produção semelhante para a safra de $2017 / 2018$ (8).

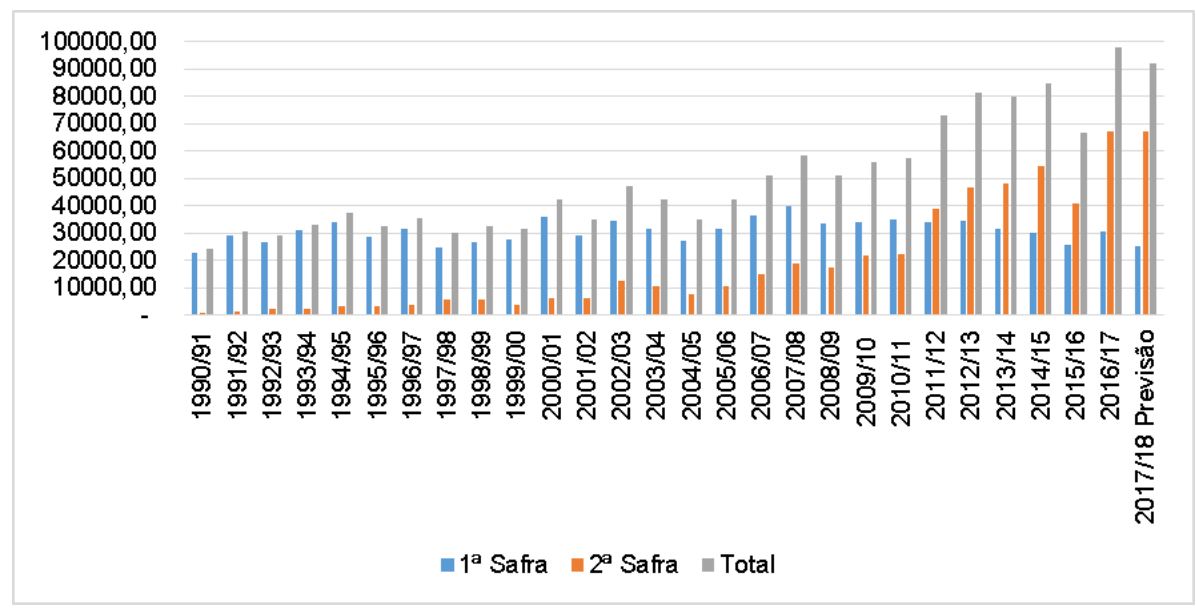

FIGURA 1

Produção de milho $1^{\text {a }}$ e 2a safra e produção total em milhões de toneladas desde 1990 a 2018 no Brasil. Adapatado CONAB (8)

Em virtude dos maiores produtores brasileiros se encontrão nas regióes Sul e Centro-Oeste, que juntos, respondem por $69 \%$ da área plantada e $75 \%$ da produção nacional, os estados com maior participação no Brasil são Mato Grosso, Goiás e Paraná, que juntos produzem cerca de 57\% do milho brasileiro. Pois muitos desses estados adotam o plantio em duas etapas: a safra tradicional, que ocorre no segundo semestre; e a "safrinha" que é produzida nos meses de fevereiro e março, sendo nesse periodo em que ocorre a maior produção como forma de diminuir a sazonalidade dos preços do milho ao longo do ano, ao contrário do que ocorre nos Estados Unidos que não dispõem dessa prática (12). 
Desse modo, é possível inferir que o crescimento de sistemas de confinamentos, somam fatores que contribuem com maior importância na utilização de grãos na elaboração de dietas na bovinocultura de corte. Dessa forma, para potencializarmos a eficiência produtiva em bovinos, a correta associação de fontes concentradas de energia e/ou proteína ao volumoso da ração de bovinos, poderá maximizar o desempenho dos animais, como efeito da complementariedade das taxas de degradação de nutrientes (13).

Utilização da Silagem de Grão Úmido de Milhos na Bovinocultura de Corte. Assim como em todo e qualquer sistemas de produção, à dificuldades inerentes, e com a silagem de grão úmido de milho não poderia ser diferente, pois também pode apresentar problemas ou impossibilidade de comercialização, com necessidade de preparo diário da dieta aos animais (14).

Todavia, bovinos confinados alimentados com dietas a base de grãos possuem certa instabilidade na população microbiana, devido às variações na produção de ácidos graxos voláteis (AGV), diminuição do poder tamponante do rúmem, visto que há menos mastigação e produção de maiores níveis de propionato e butirato (15).

Lundy et al (16) demonstram que a rápida fermentação de milho finamente moído em grande parte contribui para a risco de acidose em dietas ricas em grãos, prejudicando o desempenho de bovinos com redução do ganho médio diário. Todavia, faz-se necessário a moagem adequada de milho em dietas com baixa e alta inclusão desse alimento, com necessidade da avaliação de dietas com mais de $35 \%$ de grãos úmido ou menos do que $45 \%$ de grãos de milho na dieta. Entretanto, a digestibilidade do amido para bovinos alimentados com milho finamente moído é mais favorável, devido ao aumento da disponibilidade do amido no rúmen permitindo aos animais confinados melhor desempenho.

Ressaltando a importância da inclusão de pequena percentagem de fibra em dietas ricas em grãos, pois, ajuda a prevenir disturbios nutricionais como acidose, maximizando o consumo de energia líquida, permitindo ótimo desempenho zootécnico em confinamentos de bovinos de corte (17).

Assim, Biaggioni et al (18) demonstraram que o $\mathrm{pH}$ ideal da silagem deve estar na faixa de 3,8 a 4,2. Com a finalidade de se obter a melhor qualidade da silagem de grão úmido deve-se manter temperatura interna de $20 / 30^{\circ} \mathrm{C}$, resultando em menor produção de ácido acético. Já na ausência de pressão, $25^{\circ} \mathrm{C}$ apresenta as melhores condições em relação a qualidade final do produto, portanto, quando bem manipulado resulta em aspectos positivos referentes a utilização dessa tecnologia.

Mesmo assim, com o preço da saca de milho oscilando todos os anos, todo e qualquer produtor que tenha em sua propriedade a criação de animais em que o milho apareça como um ingrediente importante da alimentação, deve-se conhecer as vantagens da silagem de grão úmido. É, talvez, uma das poucas práticas que consegue reunir baixos custos com elevada qualidade nutricional ao longo do tempo de armazenamento, e alta resposta animal (14).

Igarasi et al (19) em experimento com bezerros machos inteiros F1 Red Angus $\times$ Nelore, em confinamento recebendo dieta total com silagem de grão úmido de milho, como ingrediente energético principal, salientam esse tipo de processamento não altera as características físico-químicas de carcaças e maciez de carne.

Do mesmo modo, reafirmando os resultados encontrados por Henrique et al (20) em que bovinos jovens submetidos a confinamento a base de silagem do grão úmido se mostra mais vantajosa, pois melhora $9,7 \%$ a eficiência alimentar, mas não alterou as características de composição da carcaça, como encontra-se na Tabela 2. 
TABELA 2

Características da carcaça dos animais em cada tratamento.

\begin{tabular}{lllll}
\hline Características da carcaça & Dietas & & & \\
\cline { 2 - 5 } & Si-MU & Si-MS & Ba-MU & Ba-MS \\
\hline Peso da carcaça quente, kg & 256 & 257,6 & 242,3 & 231,3 \\
Rendimento de carcaça, \% & 56,88 & 57,63 & 55,57 & 54,69 \\
Espessura de gordura, mm & 7,83 & 8,36 & 7,28 & 5,57 \\
Area de olho de lombo, cm2 & 62,9 & 64,52 & 60,09 & 61,03 \\
Area de olho de lombo, & 24,57 & 25,05 & 24,8 & 26,39 \\
Cm2/100 kg/carcaça & 6,21 & 5,73 & 5,83 & 5,2 \\
Peso do fígado, kg & 1,03 & 1,06 & 0,9 & 0,98 \\
Peso dos rins, kg & 8,06 & 8,26 & 6,67 & 6,71 \\
Gordura renal-pélvica-inguinal, & 8,06 & &
\end{tabular}

Silva et al (21) reportam que animais quando alimentados com dietas constituídas a partir de grãos úmidos de milho apresentam melhor eficiência alimentar $(0,160)$ em comparação a animais alimentados com milho moído (0,133), em experimentação utilizando moagem e ensilagem de grãos úmido de milho em dietas para bovinos nelores confinados.

Já Caetano (22) obteve resultando mais elevados trabalhando com o efeito do processamento do milho e dos teores de fibra no desempenho de bovinos nelore em terminação, quando utilizou silagem de grão úmido de milho obteve maior eficiência alimentar no rendimento de carcaça, quando comparado com milho moído fino, apresentando 0,145 vs. 0,130 respectivamente. Além dos resultados de desemprenho de 13,9\% superior em relação ao fornecimento de dietas de milho seco moído fino com 0,172 vs. $0,151 \mathrm{~kg} / \mathrm{kg}$ respectivamente.

De acordo com Passini et al (23), a silagem de grão úmido de milho apresenta resultados satisfatórios quando adicionada em dietas de terminação em bovinos jovens confinados, visto que não prejudica o desempenho animal, melhora as características de rendimento da carcaça e qualidade da carne, os níveis de $14 \%$ de PB na fase inicial podem ser reduzidos para $11 \%$ na fase de terminação sem prejudicar a carcaça ou a qualidade da carne.

Portella e Alves (24) trabalhando com sistemas de produção mais especializados com engorda de novilhos para o abate precoce em condições de pastejo, no terço final exige alta suplementação energética, que pode ser obtida através da silagem de grão úmido, tornando uma excelente alternativa para uso permanente em ganho em peso e acabamento de carcaça, sobretudo consideráveis reduçóes no dispendio por quilo da suplementação alimentar foram obitidos com a adição do grão úmido de milho.

Também Biaggioni et al (20) reportam que o uso da silagem de grão úmido de milho na alimentação de bovinos, há redução no consumo, pois o processamento (quebra do grão no processo de ensilagem) contribui para aumentar a disponibilidade e digestibilidade do amido no grão de milho, assim o animal consegue atender suas necessidades de energia a partir de uma menor ingestão de grãos expressando o mesmo desempenho animal. Entretanto observa-se ganhos significativos em relação a melhoria da eficiência alimentar, cerca de 9 e 25\%, obtendo resultando ainda mais consistentes em relação a conversão alimentar (18).

Segundo Gregório (25), para se obter a mesma digestibilidade na suplementação de bovinos em confinamento é necessário fornecer menos quantidades quando se utiliza o grão úmido de milho em comparação ao grão seco. Ressaltando que a partir da utilização dessa prática a disgestibilidade se torna mais eficiente e consequentemente aumento a conversão alimentar. A adoção do grão úmido também reduz os custo operacionais no confinamento, pois o grão úmido vai direto para o silo trincheira, dispensando a necessidade da secadora, assim, cada tonelada sai por $\mathrm{R} \$ 320,00$, representando um investimento de 5 a $10 \%$ de economia em relação a utilização do grão seco. 
Lopes (14) é ainda mais otimista, quando diz que a silagem de grão úmido de milho é uma técnica que vem apresentando acentuado crescimento em quase todas as regiões produtoras de milho do Brasil, com acentuada redução de custos na alimentação de bovinos de corte que pode chegar de 20 a 30\%, a partir de um consumo médio de $2,5 \mathrm{~kg}$ de grão úmido/cab/dia.

Assim como a utilização do grão úmido de milho à possibilidade de utilizar apenas um alimento e um concentrado para bovinos de corte, com redução nos gastos com produção de volumosos, mão-de-obra, infraestrutura, entre outros; ainda obter alta eficiência biológica comprovada, resultando em maior relação de arrobas produzidas com menor consumo da dieta. Mas deve-se atentar as variações na eficiência alimentar de acordo com a categoria animal utilizada, uma vez que a eficiência de transformação do alimento consumido em ganho de peso decresce, à medida que avança a idade dos animais (26).

Em níveis de 6-12\% de volumoso, indicam que pode ser substituída com sucesso em relação a Fibra em Detergente Neutro (FDN) em dietas contendo 30\% de grão úmido de milho com base da Materia Seca (MS) em terminação de bovinos, sem quaisquer efeitos prejudiciais sobre desempenho dos animais (27).

Tendo em vista que bovinos alimentados com silagem de grão úmido de milho apresentam maior peso de rúmen, quando comparado a alimentação de milho seco moído fino (10,04 vs. 9,53 kg respectivamente) (18).

Do mesmo modo, Henrique et al (20), observaram maior peso de fígado em bovinos alimentados com silagem de grão úmido de milho quando comparado ao fornecimento de milho moído seco fino.

Mesmo com riscos eminentes de desordens ruminais quando fornecido elevadas concentrações de amido, com o uso da silagem de grão úmido de milho há quatro vezes menos teor de amido fecal, quando comparado ao uso do milho seco moído com 2,96 vs. $13,22 \%$ na MS respectivamente, devido a maior facilidade do grão em ser absorvido pelas bactérias ruminais, ou seja, há melhor aproveitamento, assim menores quantidades de grão úmido chegam ate o intestino para ser digerido. $\mathrm{O}$ pH fecal também se torna mais acido quando se utiliza o grão úmido em relação ao milho grão seco moído fino sugerindo também menor passagem de amido para o intestino com 7,02 vs. 6,57, respectivamente (18).

Em relação à extensão da digestão do amido, Paulinho et al (4) compararam formas de processamento de amido, e salientaram que o milho inteiro pode apresentar digestibilidade inferior pós-rúmen, assim como o milho moído a seco quanto as digestibilidades ruminal e total, ao contrario da floculação e da silagem de grão úmido que apresentam os mais elevados índices de digestibilidade ruminal, como identifica-se na Tabela 3.

TABELA 3

Influência da forma de processamento sobre a extensão da digestão de amido de milho, em função da quantidade de amido que atingiu cada compartimento (rúmen, pós-rúmen).

\begin{tabular}{lllll}
\hline Grãos & $\begin{array}{l}\text { Tipos de } \\
\text { processamento }\end{array}$ & Rúmen & Pós-Rúmen & Total \\
\hline \multirow{3}{*}{ Milho } & Milho seco & $68.3 \mathrm{~b}$ & $71.2 \mathrm{~b}$ & $92.5 \mathrm{~b}$ \\
& Silagem de Grão úmido & $77.5^{\mathrm{a}}$ & $87.2^{\mathrm{a}}$ & $98.1^{\mathrm{a}}$ \\
& $\begin{array}{l}\text { Floculado } \\
\text { Inteiro }\end{array}$ & $83.9^{\mathrm{a}}$ & $93.9^{\mathrm{a}}$ & $99.1^{\mathrm{a}}$ \\
Fonte: Adaptado de Owens y Basalan (28). & & $57.8 \mathrm{c}$ & $90.8 \mathrm{~b}$ \\
\hline
\end{tabular}

Owens e Basalan (28) também trabalhando com relação da digestão do amido em bovinos em confinamento, apresentam valores de 78.1, 57.8 e $90.8 \%$ para digestibilidade ruminal, pós-ruminal e total, respectivamente, para o grão de milho fornecido inteiro, demonstrando a grande quantidade de milho que chega ao intestino para ser absorvida, resultando em aumento na taxa de passagem e menor absorção amido pelo animal. 
Do mesmo modo Benton et al (27), trabalhando com dietas a base de mistura de milho laminado e grão úmido de milho ensilado a partir de diferentes inclusões de volumoso na dieta total contendo $0,4 \mathrm{e} 8 \%$ na MS, obtiveram resultados de novilhas quando não alimentadas com volumoso procedendo em menor consumo de matéria seca, menor ganho peso e menor ganho de peso vivo final, sobretudo menor rendimento de carcaça e espessura de gordura subcutânea, demonstrando a importância e necessidade da utilização do simultânea do volumoso e concentrado.

Segundo Perdigão (29), avaliando bovinos Nelore machos não castrados confinados a partir dos efeitos da duração de protocolos de adaptação a rações de alto teor concentrado do qual era constituído por silagem de grão úmido de milho sobre o comportamento ingestivo, desempenho, características de carcaça e saúde ruminal, identificaram que os animais que receberam alto teor de concentrado, há necessidade de protocolos gradativos na adaptação, pelo melhor resultado no comportamento ingestivo e maior ganho de peso diário, com duração de nove dias em função de apresentar menores lesões ruminais e menor atividade ploriferativa do epitélio ruminal na terminação.

Caetano (22) analisando o efeito de quatro métodos de processamento de milho (floculado, ensilagem de grão úmido, moagem e laminação a seco) com duas inclusões de bagaço de cana de açúcar sendo constituídas de 12 a 20\% de MS da ração total, identificou maior ganho de peso, melhor valor da energia liquida referente ao fornecimento do milho floculado e a ensilagem de grão úmido de milho, apresentando também os melhores processamento para bovinos Nelore em estado de terminação.

Segundo Rizzo (30), em estudo com o efeito do teor de fibra e do processamento de grão úmido ensilado e grão seco moído fino na qualidade e perfil de ácidos graxos da carne de bovinos Nelore de dois a três anos de idade confinados, identificaram que não houve efeito do processo de ensilagem do grão úmido de milho ou dos diferentes níveis de fibra sobre a umidade, força de cisalhamento, $\mathrm{pH}$, cor, maciez sensorial, suculência e sabor da carne. Entretanto, houve um aumento no teor de lipídios na carne dos animais que receberam dietas de silagem de grão úmido de milho. Sobretudo, o aumento no teor de fibra insolúvel em detergente neutro proveniente da forragem (FDNf) na dieta resultou em menor relação $\omega 6: \omega 3$ na carne, algo desejável sob o ponto de vista da saúde do consumidor.

Entretanto, antes da escolha da alimentação a ser oferecida no confinamento, deve-se atentar ao tipo racial dos animais que serão suplementados com determinada dieta contendo alta inclusão de concentrado, pois, geralmente animais Bos Indicus apresentam desempenho inferior a bovinos cruzados ou Bos taurus, assim, aumentar a degradabilidade do amido pode tornar-se uma media bastante eficiente através da utilização da silagem de grão úmido de milho, considerando que essa pratica apresenta elevados índices de degradabilidade ruminal (31).

Caetano (22) avaliando a eficiência da energia metabolizável da ensilagem do grão úmido de milho em comparação com milho seco moído para bovinos Nelore em fase de terminação, identificou que os animais quando alimentados com grão úmido apresentaram eficiência da energia metabolizável $17,9 \%$ superior ao grão seco moído, com 60,40 e 51,23 g PV/kg respectivamente, demostrando a superioridade em fornecer energia aos animais a partir da silagem de grão úmido de milho.

Considerações Finais. A presente revisão versa sobre a viabilidade da utilização da silagem de grão úmido de milho, por se tratar de umas da poucas praticas que consegue reunir baixos custos em relação a silagem de milho convencional, aliada a elevada qualidade nutricional, sobretudo com alta resposta animal. Mesmo com as dificuldades de processamento e cuidados no armazenamento, sendo esta uma etapa fundamental na qualidade do produto a ser utilizado. Do mesmo modo, o produtor deve-se considerar o processamento a ser empregado a fim de se obter a melhor viabilidade em relação ao aproveitamento pelos animais, sempre com o objetivo de maximizar a digestibilidade do amido, sendo esta a característica de maior evidencia. 


\section{REFERÊNCIAS}

1. Santos MC, Belik W, Zen S. de, Almeida LH de. A rentabilidade da pecuária de corte no Brasil. Segurança Alimentar e Nutricional, Campinas. 2014; 21(2):505-517. DOI: https://doi.org/10.20396/san.v21i2.8634589

2. Teodoro AL, Vargas Junior FM, Oliveira MVM, Longo ML, Rufino JJ, Figueiredo TAG. Grão úmido na alimentação animal: estudo metanalítico. PUBVET Londrina. 2012; 6(4):1283-1288. http://www.pubvet.com.br/artigo/937/gratildeo-uacutemido-naalimentaccedilatildeo-animal-estudo-metanaliacutetico

3. Pereira KA, Amara AG, Oliveira AR, Arcanjo AHM, Campos JCD. Aspectos Nutricionais e Confecção de Silagem de Grão Úmido de Milho para a Alimentação de Bovinos: revisão de literatura. Revista Eletrônica Nutritime, 2017, 14(1): 4944-4953. https://www.nutritime.com.br/arquivos_internos/artigos/ Artigo_409.pdf

4. Pereira MLR. Degradabilidade ruminal In Vitro de grão reidratado e ensilado de milho e sorgo com diferentes granulometrias. [Tesis M.Sc]. Universidade Federal de Goiás, Escola de Veterinária e Zootecnia: Goiânia, Brasil; 2012. https://repositorio.bc.ufg.br/tede/handle/tde/869

5. Paulinho PVR, Oliveira TS, Gionbeli MP, Gallo SB. Dietas Sem Forragem para Terminação de Animais Ruminantes. Revista Científica de Produção Animal. 2013; 15(2):161-172. http:// dx.doi.org/10.15528/2176-4158/rcpa.v15n2p161-172

6. Lugão SMB, Bett V, Moro V, Lançanova JAC. Silagem de milho de planta inteira. In: Kiyota N, Vieira JAN, Yagi R, Lugão SMB. (editores). Silagem de milho na atividade leiteira do sudoeste do Paraná: do manejo do solo e de seus nutrientes à ensilagem de planta inteira e grãos úmidos. Londrina: IAPAR; 2011.

7. Peixoto CM. O milho no Brasil, sua importância e evolução. [em linea]. Pioneer: Brasil; 2014. URL Disponivel em: http://www.pioneersementes.com.br/media-center/artigos/165/o-milho-no-brasil-suaimportancia-e-evolucao

8. CONAB. Companhia de Abastecimento do Ministério da Agricultura. Acompanhamento da Sagra Brasileira - Grãos. Safra 2017/18. Décimo primeiro levantamento, Companhia de Abastecimento do Ministério da Agricultura: Brasília; 2018. file://C:/Users/K\%C3\%A1 rito\%20Augusto/Downloads/BoletimZ GraosZagostoZ2018.pdf

9. MAPA. Projeções do Agronegócio: Brasil 2012/2013 a 2022/2023. Projeções de longo prazo. $4^{a}$ edição. Ministérios da Agricultura abastecimento e pecuária: Brasília; 2013. http://www.agricultura.gov.br/assuntos/politica-agricola/todas-publicacoes-de-politicaagricola/projecoes-do-agronegocio/projecoes-do-agronegocio-brasil-2012-2013-a-2022-2023.pdf/view

10. Agrolink. Brasil pode dobrar a produção de milho. [em linea]. Federação da agricultura e pecuária de santa catarina - FAESC: Brasil; 2015. Disponivel em: http://www.agrolink.com.br/culturas/milho/noticia/brasilpode-dobrar-a-producao-de-milho_218087.html.

11. Wordell Filho JÁ, Elias HT. A cultura do milho em Santa Catarina. 2a Ed. Florianópolis: Epagri; 2012

12. Alves HCR, Amaral RF. Produção, área colhida e produtividade do milho no Nordeste. Informe Rural Etene, 2011; V(16). https://www.bnb.gov.br/documents/88765/89729/ire_ano5_n16.pdf/bea61fe8-4c6d-4f02ade4-21dcfd $901 \mathrm{fdf}$

13. Marafon F, Neumann M, Ribas TMB, Reinehr LL, Poczynek M, Bueno, AVL, Fianco B. Análise do efeito da colheita da planta de milho em diferentes estádios reprodutivos e do processamento dos grãos sobre a qualidade da silagem. Semina: Ciências Agrárias, Londrina, 2015; 36(5):3257-3268.

14. Lopes J. Silagem de Grão Úmido de Milho [em linea]. Câmara Municipal de Vista Gaúcha: Brasil; 2015. Disponivel em: http://www.vistagauchars.com.br/site/index.php/99-noticias/510-silagem-de-grao-umido-de-milho

15. Gobetti STC. Utilização de silagem de grão úmido na dieta de animais ruminantes. Ambiência. 2013; 9(1):225-239. https://revistas.unicentro.br/index.php/ambiencia/article/view/1304

16. Lundy EL, Doran BE, Vermeer E, Loy DD, Hansen SL. Influence of Corn Particle Size on Steer Performance and Carcass Characteristics When Fed Diets with Moderate Inclusions of Wet Distillers Grains plus Solubles. Animal Industry Report: Iowa State University; 2015. https://doi.org/10.31274/ans_air-180814-1281 
17. Galyean ML, Hubbert ML. Traditional and alternative sources of fiber - roughage values, effectiveness, and concentrations in starting and finishing diets. The Professional Animal Scientist. 2014;:30(6):571-584. https:// doi.org/10.15232/pas.2014-01329

18. BIaggioni MAM, Lopes AB de C, Jasper SP, Berto DA, Gonçalves EV. Qualidade da silagem de grão úmido em unção da temperatura ambiente e pressão interna de armazenagem. Acta Scientiarum, Agronomy. 2009; 31(3):377-382. http://www.scielo.br/scielo.php? script $=$ sci_abstract\&pid $=S 1807-86212009000300002 \& \operatorname{lng}=$ en\&nrm $=$ iso

19. Igarasi MS, Neumann M, Oliboni R, Oliveira MR. Características de carcaça e parâmetros de qualidade de carne de bovinos jovens alimentados com grãos úmidos de milho ou sorgo. R Bras Zootec. 2008; 37(3):550-558. http:// dx.doi.org/10.1590/S1516-35982008000300018

20. Henrique W, Beltrame Filho JÁ, Leme PR, Pazzaneze D, Lanna D, Alleoni G, et al. Avaliação da silagem de grão de milho úmido com diferentes volumosos para tourinhos em terminação: Desempenho e características de carcaça. R Bras Zootec. 2007; 36(1):183-190. http://dx.doi.org/10.1590/S1516-35982007000100022

21. Silva SL, Leme PR, Putrino SM, Valinote AC, Nogueira Filho JCM, Lanna D. Milho grão seco ou úmido com sais de calico de ácido graxos para novilhos Nelore em confinamento. R Bras Zootec. 2007; 36(5):1426-1434. http://dx.doi.org/10.1590/S1516-35982007000600028

22. Caetano M. Efeito do processamento do milho e dos teores de fibra no desempenho de bovinos Nelore em terminação. [Tese Doutorado]. Universidade de São Paulo, Escola Superior de Agricultura Luiz de Queiróz: Piracicaba, Brasil; 2012. http://www.teses.usp.br/teses/disponiveis/11/11139/tde-05072012-104948/ptbr.php

23. Passini R, Silveira AC, Titto EAL, Rodrigues PHM, Arrigoni M De B, Costa C, Chardulo LAL. Silagem de grãos úmidos de milho e de sorgo e níveis protéicos sobre desempenho e características da carcaça de novilhos superprecoces. Acta Scientiarum. 2002; 24(4):1147-1154. http://dx.doi.org/10.4025/ actascianimsci.v24i0.2600

24. Portella JS, Alves SRS. Silagem Ácida de Milho com Grão Úmido para Gado de Corte. Circular Técnico 24. [em linea] Embrapa: Brasil; 2002. https://www.infoteca.cnptia.embrapa.br/bitstream/doc/918708/1/ cr242002.pdf

25. Gregório M. Grão Úmido de Milho oferece boa Digestibilidade e Rendimento. [Em linea]. Canal Rural: Brasil; 2014. Disponivel em: http://www.canalrural.com.br/noticias/pecuaria/grao-umido-milho-oferece-boadigestibilidade-rendimento-8365

26. Schalch JRFJ. Terminação de bovinos confinados com dieta de milho grão inteiro. [em linea]. Beefpoint: Brasil; 2012. Disponivel em: http://www.beefpoint.com.br/radares-tecnicos/terminacao-de-bovinos-confinadoscom-dieta-de-milho-grao-inteiro/.

27. Benton JR, Erickson GE, Klopfenstein TJ, Vander KJ, Greenquist MA. Effects of roughage source and level with the inclusion of wt distillers grains on finishing cattle performance na economics. University of Nebraska, Animal Science Department: Nebraska; 2007. http://digitalcommons.unl.edu/animalscinbcr/66/

28. Owens F, Basalan M. Grain processing: gain and efficiency responses by feedlot cattle. In: Plains Nutrition Council Spring Conference. Proceedings; 2013. http://amarillo.tamu.edu/files/2010/10/2013-proceedings.pdf

29. Perdigão A. Protocolos de adaptação a rações de alto teor de concentrados para bovinos Nelore confinados. [Tesis M.Sc]. Universidade Estadual Paulista, Faculdade de Medicina Veterinária e Zootecnia: Botucatu, Brasil; 2014. https://repositorio.unesp.br/handle/11449/96662?locale-attribute=pt_BR

30. Rizzo PM. Efeito do teor de fibra e do processamento de milho na qualidade e perfil de ácidos graxos da carne de bovinos Nelore. [Tesis M.Sc]. Universidade de São Paulo, Escola Superior de Agricultura "Luiz de Queiroz". Piracicaba, Brasil; 2013. http://www.teses.usp.br/teses/disponiveis/11/11139/ tde-03052013-163328/pt-br.php

31. Marcondes MI, Valadares Filho SC, Oliveira IM, Paulino PVR, Valadares, RFD, Detmann E. Eficiência alimentar de bovinos puros e mestiços recebendo alto ou baixo nivel de concentrado. R Bras Zootec. 2011; 40(6):1313-1324. http://dx.doi.org/10.1590/S1516-35982011000600021 
Los autores permiten a RECIA reimprimir el material publicado en él. En caso de que un autor quiera traducir o usar una publicación parcial o completa de nuestro Diario, el autor debe obtener un permiso por escrito del editor de la revista.

CC BY 